\title{
Some Cautions on the US Model of Assessment in Engineering and Science
}

\author{
D. Hoole ${ }^{1,2,3}$ and S. Ratnajeevan H. Hoole ${ }^{2 \#}$ \\ ${ }^{1}$ Department of Chemistry, Central Connecticut State University, 1615 Stanley Street, New \\ Britain, CT 06050, USA \\ ${ }^{2}$ Department of Engineering and Science, Graduate Center, Rensselaer Polytechnic Institute, \\ 275 Windsor Street, Hartford, CT 06120, USA
}

${ }^{3}$ Department of Chemistry, University of Connecticut at Storrs, Storrs, CT 06269-6079, USA

\begin{abstract}
The US model of assessing students is increasingly widespread and is pushed through so called reform efforts. This model includes take-home exams, homework and group work where the independence of the student's work cannot be authenticated and is bankrolled worldwide by agencies such as the World Bank and the ADB under US influence. This paper surveys the extensive literature on academic cheating dating from the 1960s, confirms through a survey that the prevalent situation is unchanged and explains how the model works in real life, to serve as a warning to systems that blindly emulate the US model of assessment. The particular applicability of these observations to science and engineering courses is noted.
\end{abstract}

Key words: Take-home exams, ethics, faculty assessments, curricular uniformity, grading

\section{Student Assessments in Education}

Education necessarily involves some form of certification and exams are usually a part of that process. In many traditionally British Commonwealth systems, examinations were held once at the end of the year. The administration of exams from the UK, as in London External Degrees, made regular assessment impracticable. The main criticism of the system was that a) One's career was determined by one exam that sought to assess a year's learning in a few hours of testing. b) The system does not emphasize the regular work so critical to absorbing the material and relies too much on rote learning for that one annual exam c) It assesses only one type of skill (the ability to recall facts) and neither group work and the ability to work with others, nor research skills, open ended problem solving and the like.
Many systems (for example the British and the Sri Lankan) have increasingly shifted their styles of examinations. In addition, agencies like the World Bank and the Asian Development Bank which disburse funds to reform educational systems, have pushed for multiple assessment methods which are now accepted. Broadly, in Sri Lanka for example, "government-directed university reforms focus on the expansion of the university system, curriculum reform, quality assurance, staff development, career guidance, counseling, and finance. Continuous assessment will replace the final examination system traditionally used to evaluate academic progress." We praise these efforts in general, especially the shift to the semester system with midterm exams and multiple assessment systems like quizzes and midterm exams. Open-book exams allow a broader range of 
questions at exams and test the ability of the student to navigate in uncharted waters.

However, in jettisoning the old system for the American, the good things of the old system also have been thrown out. An examination of course descriptions presented to the Senate at many universities in Sri Lanka as well as the UK, US, Singapore, Malaysia, Hong Kong and Australia, shows assessment to include marks for participation, group projects, homework etc.. But how much of such group and takehome work is really the student's? When the final student transcript determines the outcome of competitions for jobs and graduate school admission, even a $10 \%$ allocation for homework can tilt the playing field.

\section{The US System and its Distinctiveness: Social Need for Graduates and Uniform Syllabi}

Although the US system has its advantages in many areas of science, its principal difference from admissions-wise restrictive systems must be taken into consideration to understand it. There was a time when universities were elitist. They catered to the very high end of society in terms of achievement in choosing their students. Standards were, therefore, easy to retain. In fact, with such intelligent students, whatever the faculty did, the students would go on to be innovative and successful in their careers. This was the model of the western university. As economies grew, however, according to World Bank estimates, at least $8 \%$ of the $18-22$ age cohort of a nation needs to be in degree programs for the country to succeed. ${ }^{2}$ As the economy surges, even more graduates are required. Table 1 shows the percentage of students in degree programs in a sampling of countries. In the US, close to $40 \%$ of the $18-22$ age cohort of the population is going through baccalaureate degree programmes. This is a much greater part of the population than in most countries, especially if one accounts for the extensive opportunities for continuing education in the US $^{1}$. It is difficult to argue therefore that the IQ

\footnotetext{
1 The OECD reports Australia, Finland, Iceland, New Zealand, Norway, Poland and Sweden over $70 \%$
}

level of the typical US graduate would match that of a graduate in countries where universities handle a much smaller group. Thus, while the elite American universities would have great choice in picking the very best of the students, the vast majority of the $3000+$ universities and four-year colleges struggle to impart writing and management skills to mediocre charges and instill work habits that enable these citizens to engage in productive employment to service the vast economy. Of course, corruption and influence peddling enable a few under-achieving students to get into some of the elite universities that cater to a small part of the population, but these universities by and large have the best scholastic achievers from high school. ${ }^{3,4}$ Equally, a few brilliant students end up in poorly ranked schools, for various reasons. Therefore, because American universities and, to a lesser extent, the universities of the developed economies, cater to more than $25 \%$ of the population, they have widely disparate achievement levels and IQs among their student population. However, in order to be successful, a university must compete for students, and this requires staking a claim for equality with the elite universities. This means a pretence to high standards, so the less competitive universities dissemble the standards of the better ones. This phenomenon is a fortiori so in the professions like engineering and chemistry where accreditation bodies like the Accreditation Board for Engineering and Technology (ABET) and the American Chemical Society (ACS) have sewn the same gown of standards tailored to fit all universities. This situation translates into high sounding syllabi and examination papers that fit the requirements and then loopholes like take-home exams, multiple forms of assessment, project work, and so on that allow most if not everyone to pass through copying. In Russia, where more than $50 \%$ of the population gets into tertiary education, "[i]f cheating were not used and if it were not tolerated by the faculty, [students] would flunk out." ${ }^{5}$ Thus, we see permissiveness towards cheating as a means 
Table 1: Enrolment in Higher Education for some Countries

\begin{tabular}{|cccc|}
\hline Country/Region & $\begin{array}{c}\text { Percentage of 18-22 } \\
\text { age group in tertiary } \\
\text { education: } 1985\end{array}$ & $\begin{array}{c}\text { Percentage of 18-22 } \\
\text { age group in tertiary } \\
\text { education: 1995 }\end{array}$ & $\begin{array}{c}\text { Percentage of 18-22 age group } \\
\text { in programs leading to a first } \\
\text { degree: } 1995\end{array}$ \\
\hline Sri Lanka & 3.7 & 5.1 & 2.22 \\
Malaysia & 5.9 & 10.6 & - \\
India & 6.0 & 6.4 & - \\
People's Republic of China & 2.9 & 5.7 & 2.0 \\
Japan & 27.8 & 40.3 & 25.4 \\
Unite d Kingdom & 21.7 & 48.3 & 24.15 \\
United States & 60.2 & 81.1 & 38.1 \\
Australia & 27.7 & 71.7 & 33.7 \\
South Africa & - & 15.9 & 7.3 \\
Nigeria & 3.3 & 4.1 & 4.1 \\
Brazil & 10.3 & 11.3 & 11.3 \\
Ecuador & 11.3 & 17.2 & 12.73 \\
\hline OECD reports (for example OECD, Education at a Glance: OECD Indicators 2007, OECD Publishing, (2007)) track these numbers as they \\
\end{tabular}

by which universities saddled with less accomplished students cope. This permissiveness is not exclusively American. Rather, it is universal to systems in which students are enrolled in large numbers. Passing most students is a market mechanism in the US and a commitment to socialist ideals in other countries. As educators who have taught in a variety of universities with very different standards, we state that the same syllabus is taught to different achievement levels, because application of the same standards would mean a high failure rate at the weaker universities leading to denial of tenure or renewal of contract for the instructor. In this race for students, technology is a means for expanding university programs, even when the problem of already having too many unqualified students has not been addressed. So called e-courses are the rage of the day despite the finding that " $E$ courses are simply correspondence courses presented with new technology" and "the student-tostudent and student-to-instructor interaction that are [sic.] missing in $E$ courses makes them less valuable to the student."7

The US campus attitude is liberal. By assuming everyone to be honest, a nice ambience is created. It is felt that it is not worthwhile to spoil this for everyone to catch the few who cheat. And those who cheat, it is claimed, should not be labeled for life; they should be given a chance to reform. Herman ${ }^{8}$ explicitly pleaded for lenience in dealing with exam misdemeanors as far back as in 1964 when the problem was much smaller, as we shall see, and it has now been settled as he wished. Thus, take-home and open book exams are encouraged, because they are said to take pressure off exams and allow the student to answer as in real life at work. Although exam pressures and the attendant stress are natural mechanisms that motivate students to study hard for an important exam, these effects are negatively perceived. To combat these effects, Parsons ${ }^{9}$ has suggested using a variety of styles of assessment, including memory support through open-book policies at exams and relaxing the time pressure on assessment (as in take-home exams ${ }^{10}$ ). These recommendations promote treating college-aged students as though they are young children who are unable to manage their own lives and emotions. In this liberal ethos, Parsons ${ }^{9}$ regrets that Asian students were especially stressed whereas in many Asian homes parents would be deeply concerned if the child were not anxious about an upcoming exam and studying hard for it. We can confirm this based on our wide experience as advisors who have had Asian parents come in to speak with us. There are also additional justifications for take-home exams. As a Rensselaer Polytechnic Institute (RPI) Adjunct Professor working as a Manager at General Electric argued, "I do not mind if they get help at exams because that is how my engineers work and I would rather hire engineers who are well networked and have the personality to get others to help them 
come up with the required solution for my team."

\section{The Enthusiastic Teacher and the Administration}

University administrations are responsible, inter alia, for keeping classrooms full, and this means filling in all vacant student slots. While third world universities have students desperate for a university education knocking to be inside, the universities catering to a large segment of the population need to attract students. Having recruited these students with filling slots as a primary goal and the scholastic abilities of the student as a mere consideration within the larger goal of keeping classrooms full, students cannot be failed out of their programs. Thus, "Retention" becomes a major index in rating a university, although its use can also be justified on grounds of measuring how a student is cared for. (In U.S. News' "National Universities" category, retention and graduation rates are worth a total of 20 percent in the current schema of ranking college excellence ${ }^{11}$ ). Once admitted, there is strong pressure from the administration to graduate the student, and softmethods are used, such as sending a failing student to a community college or summer school where we know the standards are low ${ }^{12}$ but assuming they are the same and accepting the grades from those schools without distinction.

A major grounded theory study in a nursing program finds that, although preceptors saw themselves as gatekeepers of professional standards, they failed in this role and "abdicated their responsibility ... by not assigning failing grades to students who should not have passed the course" and lost all professional and pedagogical accountability. ${ }^{13}$ These types of practices seem to be common except remain at those few top ranked US universities that can afford to impose standards as a universal norm and uphold them as such.

A huge problem is at self-financing or profitmaking master's degree courses where all and sundry are admitted without asking for standardized test scores and minimum undergraduate GPAs. Thus there are now master's courses that are entirely by written papers and no examinations. RPI, a highly ranked institution, applies rigorous admissions and course standards for graduate students but operates a separate track for engineers from industry because their employers pay their tuition bills. These MBA/MEng programs bring in $\$ 6$ million a year in profit. Although the part-timers earn the same degree, no GRE or GPA is looked at for their admission, and no research or project required to earn the M.Eng. degree. We professors are told that we are free to uphold standards, but in reality, should we fail students en masse, our classrooms would be empty as students avoid us and that would affect our raises and even continued employment saying out teaching is bad.

As underachieving universities recruit PhDholders from the elite schools to bolster the universities' standing, the recruits will initially teach the way they themselves were taught, but their expectations will not be in line with the abilities of their students. Teaching evaluations then play the part of bringing the enthusiastic teachers' expectations down to ground and in line with the capabilities of their charges - for if the new recruits fail too many students, they will be blamed saying the students are doing well in other courses. Significant grade inflation follows as welldocumented in the US ${ }^{14}$ as well as Canada. ${ }^{15}$ It is worth remarking that in the Canadian study, English and biology saw the highest inflation while mathematicians had upheld standards.

\section{Teacher Evaluations, Grading Practices, and our Confirmatory Experiments}

The preceding considerations bring us to the legitimacy of teacher evaluations, because they are affected by the grading policies of the instructor. We uphold teacher evaluations as beneficial, because when we go into class knowing that our students will be asked for their opinion of us, we teach more cautiously and carefully, and we are defensively vigilant about what can turn up in the reviews. The point however, is that typical institutional teacher evaluations are all too often done in a cavalier fashion that is more intended to keep up pretences and meet the goals of institutional economics. We have often heard the relevant rhetorical question "How many 
times have you heard of denial of tenure for poor teaching? And how many times for not bringing in research money?" The main message from a department head to one of the authors was: "Do your research and make sure there are no complaints from students." This attitude towards teaching seems to capture the ethos at many of the better universities. Teaching is rarely evaluated scientifically, as it ought to be. It is well known that better evaluations are received from students in smaller classes, at higher levels in the program, and those that are studying theoretically lighter subjects, ${ }^{16}$ yet we do not see institutions adjusting their tenure and advancement processes to account for these findings.

The extensive negative literature on methods presently used to evaluate teachers is in the public domain. It is known that there is a positive correlation between poor teacher evaluations and student expectation of lower grades in the course. Student revenge against teachers is reported: "Students give a low evaluation if they receive a low grade even when they know that most students are doing well in the course."16 In a similar finding, when, following a student evaluation of teachers, midterm grades were changed and the teachers evaluated again, there was reciprocity. ${ }^{17}$ The grades teachers received in their evaluation changed in the same direction the course grades they had given were changed. By simply giving take-home exams and higher grades, teachers can attain positive student evaluations. This seemed astounding that we needed to confirm these findings through our own studies. At Drexel University during 2006/7, the course "ECE-211: Electrical Engineering Principles" is a very difficult course to teach, because it is offered to civil engineering students. As a deliberate act of lenience, when more than half the students failed the mid-term, the exam scores were canceled and the test was administered again with similar questions. When late homework was willingly accepted, a student cried out "Good man!" in class, much to the instructor's embarrassment. The final consisted of carefully coached questions. The student assessment of the instructor was 4.5 out of 5.0 whereas the normal assessment was around 4.0 in a senior or graduate course with traditionally higher ratings. The assessment of teaching is entirely handled by the College of Engineering, and the instructors have nothing to do with it. The experiment was repeated with the course "ECEP-352: Electric Motor Control Principles" for which tests are hard and class size was close to 30 . The result was that teaching evaluations were around 3 on a scale of 1-5. A sample test was given a week before the final, and the actual final had only very slight changes from the sample. The student assessment was a perfect score of 5.0 out of 5.0, and repeated comments to the effect of "This teacher is a very fair prof" were made. This perfect score was a first such achievement for the relevant author. In the normal mode of serious teaching in an easier course, for example "ECEP-412 Power Systems II" with a class size of 10 - easier because it is a higher level course with a smaller class - the average rating was 4.0. Again, in the sophomore course, "ECE-203: Programming for Engineers," through deliberately serious and careful, punctilious teaching and strict invigilated exams, an assessment of only 4.0 out of 5.0 was obtained. In the junior course "ENGR 361: Statistical Analysis of Engineering Systems" for which class size was 100 , due to the populist Dean's intervention, late homework had to be accepted, resulting in heavy hostility with a part of the class. The resulting rating was less than 2.0, far below the instructor's norm.

Similar trials were tried with the chemistry courses "CHEM-102: Chemistry of Nutrition" and CHEM-150: Chemistry of Allied Health I" at Central Connecticut State University. The performance in $2009 / 10$ went up by $15-26 \%$ with take-home exams with respect to 2008/9 when exams were closed-book. In 2009/10, students were also pandered to by giving them the take-home exam they wished for and the class became much more receptive to the instructor than when serious teaching was done with learning as the primary goal. Similarly, in CHEM-150 when students were provided with mathematical formulae for solving problem, the outcome of evaluations was much more favorable than when the formulae were taught as material that should be recalled. 
Most disturbingly, as it ought to be for the liberal establishment that is usually in charge of universities, in a huge study in Florida that involved 10,392 classes taught by 1120 instructors, minority instructors received "significantly lower" ratings in face to face teaching, but that difference was not there in online classes. ${ }^{18}$ No other predictor showed statistically significant effects. Because persons generally find members of their own race more attractive, this finding accords well with the finding from a study conducted over four universities that professors "perceived as attractive" got 0.8 more on a 5 point scale across 4 universities. $^{19}$ That 0.8 point difference can make the difference between tenure and its denial for the instructor. Is it then not natural that when professors and students belong to the same race or ethnicity, there is an enhanced comfort level that would result in better evaluations? Is that why there was no difference in online courses and the students did not know the race of the instructor?

The evaluations also have grave implications with regard to the treatment of women. Women represent just over a half of society and bear children not for themselves only but for the men as well. Yet they bear the illeffects of marriage as far as an academic career is concerned: "Marriage and children adversely affect the likelihood that women obtain tenure-track positions. Unmarried women without young children fare better on the academic job market" ${ }^{\prime 20}$ and women have lower rates of tenure and promotion to fullprofessor. Combine this with their lower presence in the physical sciences and engineering, the unfairness of the restricted opportunities for academic positions becomes more pernicious. According to NSF (US),21 women received only $19.5 \%$ of engineering and $42.4 \%$ of physical science degrees at the bachelor's level in 2004, and at the doctoral level these numbers for the year 2006 are $20.2 \%$ and $27.8 \%$.

Moreover, "[w]omen faculty are more likely than men to work over hours because of teaching workload and rate the importance of a teaching qualification more highly, despite giving similar ratings as men to the importance of teaching to their career.."22 The tendency of women to put so much more into their teaching works against them due to the qualities valued by the committees that evaluate tenure. How does this bear on the ratings that women professors receive in engineering and physical science classes where males preponderate and presumably have a harder attitude to women than those males in the humanities and social science courses? The lead has been taken by University of Chicago in recognizing all forms of scholarship as equally legitimate bases of academic tenure, and restricting the promotion committee from considering institutional value.23 This practice ensures that women faculty who do not work late hours or who take time off for delivery and confinement do not have these tendencies held against them. We owe women fair measures of assessment.

\section{Survey of University Students}

A simple online survey was conducted that asked our undergraduate students and former students whether they cheated on take-home exams and assignments. Email lists of various undergraduate and graduate classes were used. A paid service (www.monkeysurvey.com) was used to collect the answers and tabulate them. Fig. 1 shows the finding at 213 responses. As the results were coming in, at 114 responses, at 160 responses and 213 responses, they were tabulated and there was found to be no graphically perceptible difference. The survey was taken to have converged and, therefore, closed at 213.

Subsequently, the same survey was distributed by hand by graduate students personally close to us to about 30 of their friends along with a personal request for honest answers. The admission of cheating jumped to about $76 \%$. This variation shows that in a matter as grave as admitting to cheating, the answers are sensitive, and full disclosure is made only to trusted parties. This may explain the wide variation in figures that measure confessions about cheating. However, the figures are universally disappointing. Jendrek ${ }^{24}$ finds that $40 \%$ to $90 \%$ of postsecondary students admit to academically dishonest behavior, and Graham et al. ${ }^{25}$ also report a figure consistent with ours and Jendrek's (89\%). McCabe who has studied the problem over several decades 


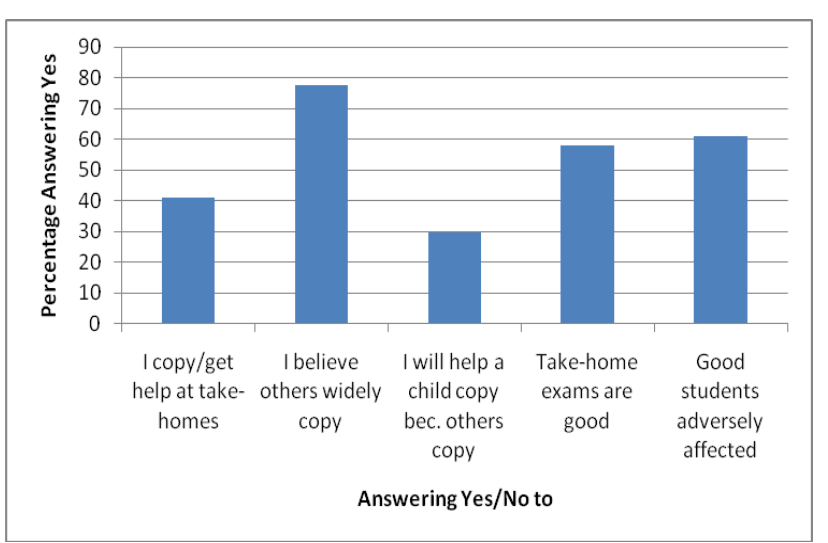

Figure 1: Responses to our Survey on Take-Home Exams (Summary of 213 Responses)

reports that " $75 \%$ of college students admitted to cheating." ${ }^{26}$ The confluence of these studies in their essential conclusion is inexorably inescapable - that cheating is a real problem, even though we in engineering and the sciences keep silent on the subject. Cheating is corrosive, "[w]hen most of the class is cheating on a difficult exam and they will ruin the curve, it influences you to cheat so your grade won't be affected." ${ }^{27}$ This justification is reported as a common reason for cheating. ${ }^{28}$ Students ignore and condone peer cheating, because they recognize the great pressure and competition that all students face and empathize with those who cheat as a coping mechanism. ${ }^{29}$ The extensive prevalence of cheating, means that "nearly everyone is doing it," ${ }^{30}$ and, because many teachers do nothing in the face of cheating, "the chances of getting caught are slim and the further chance of harsh punishment is nil." $" 30$

Generally one encounters older people saying that things were better in their time, and, all too often, it merely reflects their wistful nostalgia for the past. Professors complain that they cannot teach as deeply as they used to, but that observation can be explained by syllabus coverage being made up through many more subjects because of the expansion of knowledge. However, with regard to copying, the evidence of deterioration is real. Helping others cheat had climbed from $23 \%$ in 1964 to $37 \%$ at the same campuses in $1994 .{ }^{31}$ Similarly, a historical comparison shows that in

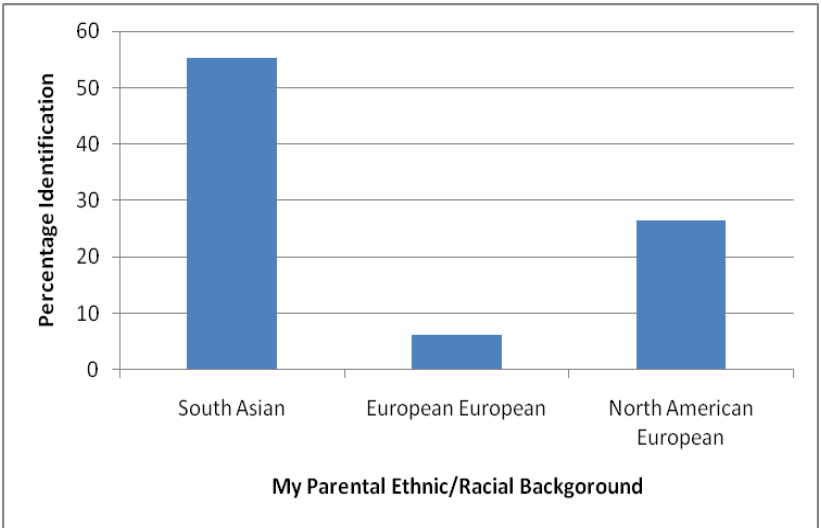

Figure 2: Racial/Ethnic Identity of our Survey Respondents

$1969,33 \%$ of high school students cheated, and by 1999 that had risen to $67.8 \%{ }^{32}$

That $40 \%$ to $90 \%$ of students admit to copying is, by itself, a strong indictment of the grades we give our students. Without further studies on the extent to which this cheating affects the objectivity of grades, these grades must remain suspect. Almost $80 \%$ of students believe that others copy (Fig. 1), and, therefore, we may infer that the students themselves have no confidence in these takehome exams. One may also discern an additional concern when it is realized that $60 \%$ of students report believing that take-home exams are a good practice while $80 \%$ believe that students cheat (Fig. 1). This implies that they do not care. As McCabe estimates, " $85 \%$ of students just want the degree itself and do as little as possible to get it." ${ }^{26}$ This too confirms our earlier perceptions.

Further, the majority of the students to whom the web-based survey was distributed were over $50 \%$ Euro-Caucasian, as is typical in a US undergraduate engineering or science program. Yet, the South Asians formed the majority of the respondents (Fig. 2), which shows that affinity to and comfort levels with the surveyors are indeed factors in being forthcoming. Similarly, there were many students of Far East origin, but their response rate was as low as that of the European Europeans (i.e., Euro-Caucasians born in Europe) as a percentage of the returns but very small in terms of response rate. This finding prompted us to mail surveys to 
students at Swinburne University of Technology's Sarawak Campus and using professional acquaintances as intermediaries to distribute the surveys, but there was no perceptible increase in returns. Because the variation in reported figures was so extensive, a deeper study is required. We may take it, however, that copying is, indeed, extensive.

\section{Survey through a Graduate Course - Distance Education}

"ECSE-6770: Software Engineering I" is a required course for all master's students studying computer science at RPI under an author. Catering to face-to-face (F2F) and Distance Education (DE) students, the F2F lectures delivered at Hartford, CT were taped live with and including student interventions and made available on the Blackboard online class management software. As run for the project being reported here, it closely followed the course text, because DE students lack the benefits of F2F formats and, therefore, must be given textbooks from which to follow the course. The course was run with 21 students in the F2F session (all of whom were part-time master's degree candidates) and another 26 participating as fully DE students. The latter group involved a majority of full-time graduate students and 2 advanced undergraduates, all from the mother campus in Troy, besides parttime master's degree candidates.

Because working professionals tend to have their attention divided between work and study and are often quite tired when they come to class after a full day's work, the contextual factors that describe these students would normally cause one to expect the DE students to be the stronger class. Superior performance by DE students has been reported $^{33}$ and the "generally positive learning experience" and "[effective] promotion of student learning" under DE. ${ }^{34}$

This class composition provided a basis for comparison of experiences in the F2F and DE modes of lesson delivery. The continuous system of assessment provided data points from homework assignments every or every other week as well as mid-semester and final exams, and many additional data points were available that could be used to compare DE students with F2F students. The end of term project was not considered because it was done in teams that involved a mix of DE and F2F students. At the invigilated exams/tests administered to both groups, the $21 \mathrm{~F} 2 \mathrm{~F}$ students had an average score that was $7 \%$ points above that of the average score earned by the $26 \mathrm{DE}$ students. This is consistent with the differences between invigilated and takehome exams that were independently reported after our study was completed. ${ }^{35}$ In our multiple homework assignments and the final take-home exam there was no difference in average performance ( $<1 \%$ difference). These findings run contrary to Llija's findings ${ }^{33}$ that the DE students fared better. The finding that homework marks were not markedly different for the two groups, yet the exam marks had a startling difference may be due to outside help, which is consistent with our finding. We also believe that our findings indicate that when the exam allows students to get help, all students, both F2F and DE, do get help, but apologists for the system attribute the better performance at take-home exams to the absence of exam stress.

Wachenheim's findings ${ }^{35}$ are consistent with ours respect to the following: a) Students taking a course in the classroom perform better than online students on a proctored exam, and b) When the online class was given an uninvigilated exam, they scored one letter grade better than those taking an invigilated final. For us too, the $7 \%$ difference seen here reflects only a difference of about one letter grade (although normally it would be more), because the examinable portion of the course accounted only for $50 \%$ of the grade so that the $7 \%$ advantage at take-home exams becomes an advantage of $3.5 \%$. In fact, in one RPI graduate course on high voltage engineering, the pass rate went to $100 \%$ when a second exam was given because half the class failed the first, and the difference was more than one full letter grade. At Central Connecticut State University, when all exams were invigilated one term and the next term the same courses permitted take-home tests, the marks jumped $15-26 \%$, depending on the student.

Likewise Marsh, ${ }^{36}$ in the early days of studies on take-home exams, split his study group into Group A, which was given a take-home exam, 
and Group B, which was given a proctored exam. A week later both groups were given an unannounced proctored test. Group B achieved better. The significance, according to Marsh, is that those who do proctored exams learn/retain more of the material by studying harder, and, therefore, the pedagogic justification for in-class exams is better. Curiously, Marsh does not comment on any differences between Group A and Group B in the initial tests, nor do the reviewers of his paper appear to have asked for such discussion (as would seem to have been natural for them to do) to justify attributing the differences in performance on the last test to the format of the earlier test rather than some other factor. Was Marsh quietly undermining take-home tests on other grounds while avoiding open accusations of cheating? Wachenheim ${ }^{35}$ also appears to have played this game in trying to explain the reasons that students earned higher marks on take-home exams. Although cheating is the more obvious answer, she discusses issues such as students "cheating themselves" by not studying hard for take-home exams, the testing environment, etc.. We attribute these rationalizations to a system that is unwilling to admit and deal with widespread cheating.

\section{Importance in Engineering, Science and Computer Science}

The questions raised above are especially important in engineering, science, and computer science programs for three reasons. The first concerns removing obstacles to under-represented minority teachers in engineering and the hard sciences. We have just alluded to removing the special obstacle that our teacher evaluations present to women who are under-represented and are already suffering, as noted. ${ }^{20-22}$ The use of unscientific teacher evaluations also negatively affects instructors of color because of the connection between race and good or bad evaluations, as reported in the above-cited Florida study comparing anonymous instructors in online courses with instructors of known race in F2F teaching. ${ }^{18}$

The second reason concerns the ill effects of take-home exams on minority students, African Americans in particular, who are under-represented, and their retention. While teaching at Harvey Mudd College, one of us worked with the then Dean on the problem of retaining African American students. African American students were admitted by the same standards but soon tended to drop out of the program. The relevant writer used his graduate students to arrange special classes, but they were not successful and the two students who were tutored dropped out. At the time, the keyword was networking. We felt that a minimum number of a community needs to be present on campus for students of that community to succeed. In a study conducted at University of Peradeniya as part of our efforts to get women into computer engineering, we found that women engineers, even when in significant numbers $(15 \%$ of a class of 320 ) lost the ability to network because they were distributed throughout dorms where arts students were dominant. ${ }^{37}$ Men on the other hand were well networked, because most engineering majors were housed in one dorm. We also found that the few female students with male friends in the same hard-science special degree program were more likely to earn a degree ultimately. These considerations once again relate to the subject of take-home exams. When we permit take-home exams knowing that students copy, whom do isolated minorities copy from? The author at Central Connecticut State University looked at the results of take-home exams for isolated minorities in class and found that these students performed relatively poorly on these types of assessment while other students benefited from that exam format.

The third reason for the importance of the subject for engineering and the hard sciences is that a good portion of the work in these areas is done in groups and, in the case of long assignments and tests that cannot be invigilated because of the length of time, at home. Prof. Tom Axford in his review of a computer science program states, "Approximately one third of the computer science content should be practical work. In other words, about one third of the student's effort should be devoted to developing software himself or herself. ${ }^{38}$ Clearly much of such work would be done outside hours, and the question of independent effort becomes paramount in grading one student against another. 


\section{Conclusions}

Older studies showing cheating to be widespread have been shown to be valid to this day. This finding has ramifications to countries where a) reforms are pushed and programs rapidly expanded, b) teacher evaluations pressed without understanding the dynamics of gender and race in responses (especially in societies riven by ethnic strife), and c) e-programs are expanded where there

\section{References}

1. Education Encyclopedia, "Global Education Reference - Sri Lanka," http://education.stateuniversity.com

2. UGC, National plan for the university sector in Sri Lanka, UGC, Colombo (2004).

3. D. Golden, The price of admission: How America's ruling class buys its way into elite colleges--and who gets left outside the gates, New York: Random House (2009).

4. M.A. Hernandez, $A$ is for admission: The insider's guide to getting into the Ivy League and other top colleges, Warner Books (1997).

5. UNESCO, Education trends in perspective: Analysis of the world education indicators, UNESCO: Paris (2005)

6. D.R. Robert, A Journal of Soviet and East European Studies, No. 51, p. 26, (1964).

7. G. Saunders and R. Weible (1999.) Internet Research, Electronic Networking and Applications, 9(5) 339-347 (1999).

8. A.L. Herman, Journal of Higher Education, 7(5) 260-266 (1966).

9. D. Parsons, Int. J. Eng. Educ., 24(6) 1111-1118 (2008).

10. L. Hall, Journal of Management \& Organization, 7(2) 50-57 (2001).

11.M. Landsverk, The Minnesota Daily, Oct. 14 (2009).

12. L.W. Lackey and W.J. Lackey, Int. J. Eng. Educ., 22 (1) 130-139 (2006).

13. F. Luhanga, O.J. Yonge and F. Myrick, Int. J. Nursing Education Scholarship, 5(8) (2008).

14. B.R. Rush, R.G. Elmore and M.A. Sanderson, J. Vet. Medical Educ., 36(1) 107-113 (2009).

15. P.M.Angling and R. Meng, Canad. Pub. PolicyAnalyse de Polit., 26(3) 361-368, (2000). is no guarantee that the students' submissions are really their own. Means other than takehome exams and assignments must be found to pursue the laudable goals of examining an array of skills in students such as the ability to work in a group, open ended problems that take time, etc.. Take-home assignments should be graded on a pass/fail basis to avoid tainting the relative standing of students. In emulating the US system, we must pick only those aspects that make good sense.

16. G. A. Boysen, Teaching of Psychology, 35(3) 218-222 (2008).

17. D.E. Clayson, T.F. Frost and M.J. Sheffet, Acad. Mangmnt and Learning, 5(1) 52-65 (2006).

18. A.C. Carle, Computers and Education, 53(2) 429-435 (2009).

19. T.C. Riniolo, K.C. Johnson, T.R. Sherman, and J.A. Misso, Journal of General Psychology, 133(1) 19-35, (2006).

20. N.H. Wolfinger, M.A. Mason, and M. Goulden, J. of Higher Education, 79(4) 388- (2008).

21. NSF, Science and Engineering Statistics, Washington DC (n.d.).

22. Z. Todd, A. Madill, N. Shaw, and N. Brown, Sex Roles, 59(11-12) 765-775 (2008).

23. M.E. Feder, and J.L. Madara, Academic Medicine, 83(1) 85-95 (2008).

24. M.P. Jendrek, Journal of College Student Development, 30, 401-406 (1989).

25. M.A. Graham, J. Monday, K. O'Brien and S. Steffan, Coll. Stdnt Dev., 35, 255-260 (1994).

26. D.L. McCabe, Change, 28, 28-33 (1996).

27. L.G. Paldy, Journal of College Science Teaching, 26(26) 4-6 (1996)

28. D.L. McCabe, L.K. Trevino and K.D. Butterfield, J. of Higher Educn., 72(1) 29-45 (2001).

29. J.C. Dalton, J.C., in D.D. Burnett, R.L. Burnett, and K.O. Cliffords (Eds), Academic Integrity Matters, Washington DC: Ntl. Assoc. of Student Personnel Administrators (1998).

30. G.J. Cizek, Cheating on tests, Lawrence Mahwah, NJ: Erlbaum (1999).

31. D.L. McCabe and W.J. Bowers, Journal of College Student Development, 35(1) 5-10 (1994). 
32. G.C. Altschuler, New York Times, Sunday Jan. 7, Sect. 4A, p. 15, col. 1. (2001).

33. D.J. Llija, IEEE Trans. Educ., 44(1) 35-40 (2001).

34. A.W. Bangert and L. Easterby, Nurse Educator, supplement S (2008).

35. C.J. Wachenheim, Review of Agricultural Economics, 31(3) 640-652 (2009).
36. R. Marsh, Journal of Educational Research, 78(2) 111-113 (1984).

37. D. Hoole and S.R.H. Hoole, Society of Women Engineers, 47(6) 51-57 (2001).

38. T. Axford, Report to the engineering faculty board Peradeniya, B'ham, May 17 (2001). 